DOI: 10.21892/978-958-5547-64-3.5

\title{
5. Competencia económica y derecho de la competencia: las prácticas restrictivas de la competencia en el derecho colombiano
}

Iván Humberto Galvis Macías ${ }^{1}$

\section{Introducción}

Las principales discusiones en torno a la elección de un determinado modelo económico que produzca mejor distribución de los recursos o, en otras palabras, que genere eficiencia en la asignación de recursos escasos, han girado en torno al desempeño y las relaciones que cumplen los agentes económicos en la interacción económica, y también al papel que el Estado ejerce frente a tal interacción en los diferentes mercados.

De esta afirmación se pueden abstraer, al menos, tres ideas principales: i) Para la consecución de una asignación eficiente de recursos se requiere de la interacción de los agentes económicos, quienes deben concurrir al mercado - según sus restricciones presupuestales (para el caso de los consumidores) o incluso operativas o de producción (para el caso de los productores) - con el fin de satisfacer sus necesidades o intereses, de acuerdo con la posición que cada uno ostente en la relación económica; ii) El escenario propicio para la generación de la interacción económica es el mercado y, con ello, de la asignación de recursos; iii) La interacción entre Estado y mercado no ha sido una circunstancia apacible en el estudio de la teoría económica, pues distintos modelos económicos - a lo largo del desarrollo de esta - han defendido posiciones encontradas.

Sin embargo, aunque el debate se genere en torno de la conveniencia en la aplicación de modelos económicos que propendan por el libre mercado o de aquellos que se fundamenten en la planificación económica.

1 Abogado de la Universidad Santo Tomás. Especialista en Derecho Constitucional de la Universidad Nacional de Colombia. Especialista en Contratación Estatal de la Universidad Santo Tomás. Magíster en Derecho con énfasis en Derecho Económico de la Universidad Externado de Colombia. 
Lo cierto es que la mayoría de economías del mundo aplican los postulados más importantes propuestos por los clásicos, aunque ellos se entrelacen con postulados de la teoría keynesiana.

Lo anterior permite inferir - sin temor a equivocarnos - que, en las actuales economías del mundo, existen muy pocos casos - por no afirmar que ninguno - en los que se pueda evidenciar la aplicación de un modelo puramente libremercadista, en el que la intervención del Estado sea nula o extremadamente escasa, y una minoría de casos en los que el modelo económico aplicable, se fundamenta estrictamente en las premisas de las economías planificadas.

Con ello, las principales ideas de la teoría económica clásica encuentran aún hoy múltiples escenarios propicios para su aplicación, bajo la premisa de la defensa del libre mercado y bajo la defensa de la teoría del libre juego de la oferta y de la demanda propuesta por Smith, en su célebre obra "Una investigación sobre la naturaleza y causas de la riqueza de las naciones" (1776).

De esta manera lo expresa Stiglitz cuando afirma que:

En la mayoría de las economías industriales modernas, la producción y la distribución de bienes recae en el sector privado más que en el sector público. Uno de los principios más duraderos de la ciencia económica sostiene que este tipo de organización asigna eficientemente los recursos (2000, p. 67).

Con todo lo anterior, el mercado constituye el escenario más importante para la generación de eficiencia económica, e incluso para la consecución del desarrollo económico de los estados, por lo que su protección y defensa no compete exclusivamente a los agentes que se relacionan en él y por él, sino que llega también a la órbita de competencia de la autoridad estatal, quien debe propender en garantizar las relaciones libres de mercado y sancionar a quienes las restrinjan o cercenen.

De lo anterior expuesto se evidencia la necesidad - y así se procederá - de: i) Analizar el presupuesto fundamental para garantizar estas relaciones libres de mercado que se concreta en el concepto de competencia económica; 
ii) Determinar cuáles son los principales instrumentos que reconocen a la competencia como un derecho subjetivo en el ordenamiento jurídico colombiano; iii) Examinar los distintos instrumentos o instituciones a través de los cuales el Estado cumple con su función de garantizar el ejercicio de la libre competencia y de la libertad económica, refiriéndonos de manera específica a la regulación de las denominadas prácticas restrictivas de la competencia.

La última parte de este trabajo corresponderá a un análisis conceptual que se desarrollará a través de las posturas teóricas que explican cada uno de los grupos de conductas restrictivas, y adicional a ello se intentará abordar cada grupo (actos, acuerdos y abuso de la posición de dominio) haciendo referencia a casos estudiados por la Superintendencia de Industria y Comercio, quien en nuestro ordenamiento funge como la autoridad de competencia.

\section{La competencia económica y el derecho de la competencia}

El marco de protección y garantía de las relaciones libres de mercado debe partir del entendimiento que - desde la teoría económica - se les ha dado a estas relaciones, para lo cual se emplea como referencia la definición emitida por Mankiw, quien define los mercados como: "[u]n grupo de compradores y vendedores de un bien o servicio en particular [en el que] Los compradores son el grupo que determina la demanda del producto y los vendedores son el grupo que determina la oferta de dicho producto." (2012, p. 66).

Sin duda, es necesario hacer referencia a la competencia económica y al derecho de la competencia como mecanismo de regulación para el correcto funcionamiento de los mercados y de la participación de los agentes económicos en ellos. Se debe partir de un reconocimiento conceptual de la competencia, y de una definición de las principales características económicas que se le atribuyen, y de esta manera entender el porqué de la necesidad de reconocerla como un auténtico derecho y, por ende, de promoverla y garantizarla con efectividad, a través de mecanismos jurídicos de protección. 


\subsection{El surgimiento del concepto de competencia}

La competencia, como concepto esencialmente económico, presenta hoy en día diversos elementos que constituyen una apreciación de carácter jurídico, adquiriendo su más evidente reconocimiento en los postulados de la teoría económica clásica y, específicamente, en las ideas consolidadas en el estudio económico del filósofo y pensador escocés Adam Smith.

Así lo reconoce Stiglitz:

En 1776, Adam Smith afirmó en la primera gran obra de la economía moderna $\mathrm{La}$ riqueza de las naciones, que la competencia inducía a los individuos, en la búsqueda de sus propios intereses privados, a fomentar el interés público, como si fueran conducidos por una mano invisible. (2000, p. 67).

De esta manera, la célebre metáfora de la mano invisible propuesta por el pensador del siglo XVIII, a través de la cual el mercado goza de facultades de autorregulación a partir del libre juego de la oferta y la demanda, constituye el principio y fundamento para acoger a la competencia como un concepto esencial en el desarrollo de las relaciones económicas.

Así lo describe el padre de la economía clásica cuando, al hacer un análisis de los precios de mercado (precios a los cuales se intercambia un bien y que puede estar por debajo o por encima de los precios naturales del mismo) y de los precios naturales (precio que sirve para cubrir las tasas medias de salario, renta y ganancia) de los productos, según lo cual afirma lo siguiente:

Cuando la cantidad de cualquier mercancía llevada al mercado es menor que la demanda efectiva, todos aquellos que están dispuestos a pagar el valor completo de la renta, los salarios y el beneficio que deben ser pagados para llevarla al mercado, no podrán ser suministrados con la cantidad que desean. En lugar de pasarse sin ella, algunos estarán dispuestos a pagar más. Se establecerá inmediatamente una competencia entre ellos, y el precio de mercado subirá más o menos por encima del precio natural, según que la mayor o menor escasez, o la riqueza y el deseo de ostentación de los competidores anime más o menos su afán de competir. (...) Cuando la cantidad 
traída al mercado excede la demanda efectiva, no podrá ser totalmente vendida a los que están dispuestos a pagar el valor total de la renta, salarios y beneficios que deben ser pagados para llevarla al mercado. Una parte deberá ser vendida a los que están dispuestos a pagar menos, y el precio menor que pagarán por ella deberá reducir el precio del conjunto. El precio de mercado se hundirá más o menos por debajo del precio natural. (...) Cuando la cantidad traída al mercado es exactamente suficiente para satisfacer la demanda efectiva y nada más, el precio de mercado llega a coincidir precisamente, o tan precisamente como pueda pensarse, con el precio natural. (Smith [1776] 1994, p. 98).

Sin embargo, este no es el único reconocimiento percibido en favor de la competencia a lo largo de la obra de Smith. El autor también hace lo propio cuando analiza los beneficios que se pueden obtener del capital, al reconocer que:

Cuando los capitales de muchos comerciantes ricos son invertidos en el mismo negocio, la mutua competencia naturalmente tiende a rebajar el beneficio; y cuando existe un aumento similar en todos los negocios de la sociedad, la misma competencia ejerce el mismo efecto sobre todos ellos. (Smith [1776] 1994, p. 138).

De esta manera, el concepto de competencia encuentra singular importancia en la defensa de la autorregulación del mercado, pues es a través de ella como la oferta y la demanda se adecúa para satisfacer las necesidades de los demandantes y, al mismo tiempo, para satisfacer los intereses perseguidos por los oferentes de un producto determinado.

Esta proposición encuentra soporte teórico en las afirmaciones de Brue y Grant, quienes exponen que:

La clave para comprender el concepto de la mano invisible de Smith es el concepto de competencia. La acción de cada productor o comerciante que trata de ganar una utilidad está frenada por los otros productores o comerciantes que de la misma manera intentan ganar dinero. La competencia baja los precios de los bienes $y$, al hacerlo, reduce la utilidad recibida 
por cada vendedor. En situaciones en las cuales al inicio sólo hay un vendedor, la extraordinaria utilidad atrae a nuevos competidores que incrementan la oferta y borran la utilidad excesiva. En una forma análoga, los patrones compiten con otros por los mejores trabajadores, los trabajadores compiten entre ellos por los mejores trabajos y los consumidores compiten unos con otros por el derecho de consumir productos. Dicho en términos económicos contemporáneos, el resultado es que los recursos se asignan a sus usos de valor más alto; prevalece la eficiencia económica. (2009, p. 67).

De esta manera, la competencia genera beneficios para los consumidores o demandantes de los productos y, a la vez, genera incentivos para que los productores de los mismos busquen captar la atención de los demandantes. De manera tal que puedan dirigir las decisiones de consumo de los primeros hacia las necesidades que satisfagan los productos de los segundos, generándose de esta manera, precisamente, una autorregulación del mercado.

Sin embargo, y a pesar de haber entendido el antecedente más importante del concepto de competencia económica, aún hace falta precisar lo que debe entenderse en el contexto de la interacción de los agentes económicos. Para este propósito Mankiw afirma que:

Los economistas utilizan el término mercado competitivo para describir un mercado en el que hay múltiples compradores y vendedores $y$, por tanto, individualmente ninguno de ellos tiene un impacto significativo en el precio del mercado. Cada vendedor (...) tiene control limitado sobre el precio porque los otros vendedores ofrecen productos similares. Así, el vendedor tiene muy pocas razones para reducir el precio, pero si decide incrementarlo, los compradores acudirán a comprar (...) a otro lugar. De la misma manera, un comprador no puede modificar el precio al que se vende [el producto] porque solamente compra una pequeña cantidad de este bien. (2012, p. 66).

En este orden de ideas, por competencia económica debe entenderse la posibilidad que tienen los agentes económicos (demandantes y oferentes; consumidores y productores o comercializadores) de acudir al mercado, 
sin que tal concurrencia implique la facultad de modificar los precios de un producto homogéneo que también es ofrecido por múltiples oferentes. Esto quiere decir que en el mercado competitivo los agentes económicos son precio aceptantes, pues, si pudiesen influir en la determinación de los precios de los productos que se transan, se estaría ante un mercado cuya característica principal no es la libre competencia, vale decir, frente a otras estructuras de mercado que, por supuesto, también requieren de la regulación del Estado (monopolios, duopolios, oligopolios, entre otros).

\subsection{La competencia perfecta}

Uno de los fundamentos teóricos que sirven para comprender el funcionamiento de la competencia económica, y con ello, la necesidad de intervención del Estado para su garantía es el supuesto de la competencia perfecta, proposición en la que se basaron las principales ideas de la teoría económica clásica, pues, como lo reconocen Krugman, Wells y Graddy: “[e]l modelo de oferta y demanda (...) es un modelo de un mercado perfectamente competitivo." (2013, p. 198).

La competencia perfecta entiende entonces que todos los mercados tienden a tener pluralidad de oferentes y pluralidad de demandantes, lo que hace que se consolide un escenario de competencia que implica la autorregulación del mercado de acuerdo con los comportamientos de la oferta y la demanda.

De esta manera, la competencia perfecta se da, en términos económicos, cuando:

(...) la escala eficiente mínima de un solo productor es pequeña en relación con la demanda del bien o servicio. En esta situación, hay espacio en el mercado para muchas empresas. La escala eficiente mínima de una empresa es la cantidad de producción a la cual el costo medio en el largo plazo alcanza su nivel más bajo. En la competencia perfecta cada empresa produce un bien que no tiene características únicas, de tal manera que a los consumidores no les preocupa a qué empresa comprarle. (Parkin, 2014, p. 272).

En tal sentido, el postulado de la competencia perfecta supone que la producción de un oferente en el mercado, representa solo una mínima 
porción del producto disponible para la satisfacción de la demanda efectiva de ese producto. Es decir, la cantidad de producto aportada por un solo oferente sirve solamente para satisfacer una mínima parte de la cantidad de producto demandada en el mercado. Producto que por su parte es homogéneo, vale decir, que no ostenta cualidades únicas que hagan que nada más pueda ofrecerlo una o pocas empresas en el mercado.

Con ello, la imposibilidad de que un solo oferente pueda satisfacer gran parte de la demanda efectiva de un producto y las características homogéneas del mismo, hacen que una pluralidad de empresas concurran al mercado a ofrecer el mismo producto a los consumidores, quienes, a su vez, por la pluralidad de empresas oferentes, no pueden incidir en el precio del producto.

De esta manera, Pindick y Rubinfeld (2009) establecen los tres supuestos básicos en los que se soporta el modelo de competencia perfecta, a saber:

i. Las empresas son precio-aceptantes: "Como cada empresa vende una proporción suficientemente pequeña de la producción total del mercado, sus decisiones no influyen en el precio de mercado. Por tanto, cada una considera dado el precio de mercado." (p. 306), y de la misma manera lo son los consumidores, pues cada consumidor en el mercado puede comprar una porción tan pequeña del producto que con ello no puede influir en el precio de mercado (p. 306);

ii. El producto es homogéneo: lo que por su parte quiere decir que los productos son idénticos o casi idénticos (p. 306), por lo que ninguna empresa oferente puede subir el precio del mismo, pues el consumidor encontrará con facilidad otras empresas que lo vendan a un precio más cómodo. "El supuesto de la homogeneidad del producto es importante porque garantiza que hay un único precio de mercado, coherente con el análisis de oferta y demanda." (Pindick \& Rubinfeld, 2009, p. 307); y

iii. Existe libertad de entrada y salida del mercado: Lo que implica que no existen barreras o costes que impidan que una empresa entre o salga del mercado cuando no perciba utilidad. "Como consecuencia, los compradores pueden cambiar fácilmente de 
proveedor y los proveedores pueden entrar o salir fácilmente del mercado." (Pindick \& Rubinfeld, 2009, p. 307).

Desde tales postulados del modelo de competencia perfecta, se supone que la mayoría de mercados - o al menos casi todos - encuentran sus puntos o precios de equilibrio en la relación dinámica de la oferta y la demanda. Y, por lo mismo, los recursos son asignados de manera eficiente entre quienes los demandan.

Sin embargo, la realidad económica muestra que la teoría de la competencia perfecta no es más que el calificativo que en este texto se le ha dado: un supuesto que puede ser desvirtuado, pues como lo afirma Mankiw: "(...) no todos los bienes y servicios se venden en mercados perfectamente competitivos. Algunos mercados tienen un solo vendedor $y$ es este vendedor, denominado monopolio, el que fija el precio." (Mankiw, 2012, p. 67). Por esta razón, resulta relevante hacer un breve análisis acerca de las causas que generan la necesidad de que el Estado intervenga en favor de la competencia económica.

\section{3. ¿Por qué regular la competencia?: El derecho de la competencia}

Tirole ha reconocido expresamente que: "[1] os economistas siempre han alabado los méritos de la competencia en aquellos mercados en donde se puede ejercer." (2017, p. 381), afirmación de la cual se puede inferir - como también lo reconoció Mankiw (2012) - que aquel supuesto de competencia perfecta no es aplicable a todos los mercados y, por lo tanto, existen estructuras de mercado en las que no se evidencian los presupuestos básicos de este tipo de competencia, definidos previamente por Pindick y Rubinfeld (2009).

En tal sentido, afirma Tirole que:

(...) la competencia raramente es perfecta, los mercados tienen fallos, y es necesario frenar el poder del mercado - es decir, la capacidad de las empresas de fijar sus precios por encima de sus costes o de ofrecer prestaciones de escasa calidad -. Tanto sus partidarios como sus detractores olvidan en ocasiones que la competencia no es un fin en sí misma. Es un instrumento al servicio de la sociedad y, si provoca falta de eficacia, debe ser dejada de lado o corregida. (2017, p. 381). 
Desde esta perspectiva se reconocen dos realidades que ya han sido corroboradas por los acontecimientos desarrollados en la historia económica moderna. Primero, los mercados - en ocasiones - no responden a la dinámica autorregulatoria propuesta por la teoría económica clásica y, por el contrario, se enfrentan a la experimentación de fallas, pues, como lo expresa Stiglitz:

El primer teorema fundamental de la economía de bienestar establece que la economía solo es eficiente en el sentido de Pareto en determinadas circunstancias o condiciones. Hay seis importantes condiciones en las que los mercados no son eficientes en el sentido de Pareto. Se denominan fallos del mercado y constituyen un argumento en favor de la intervención del Estado. (2000, p. 92).

Segundo, tal y como lo expresó Stiglitz, el acaecimiento de las fallas del mercado, constituye - además de un argumento favorable - el fundamento de la intervención del Estado para corregir estas fallas, y entre tantos instrumentos disponibles para ello, como la institucionalización del denominado derecho de la competencia, ya que el mismo autor reconoce que es el fallo de la competencia uno de los seis fallos del mercado, según el cual:

Para que los mercados sean eficientes en el sentido de Pareto, tiene que haber competencia perfecta, (...) Pero en algunos sectores - superordenadores, aluminio, cigarrillos, tarjetas de felicitación - hay relativamente pocas empresas o una o dos tienen una gran cuota de mercado. Cuando hay una única empresa en el mercado, los economistas la llaman monopolio; cuando hay unas cuantas, los economistas las denominan oligopolio. E incluso cuando hay muchas, cada una puede producir un bien algo distinto y pueden pensar, pues, que se enfrenta a una curva de demanda de pendiente negativa. Los economistas llaman competencia monopolística a estas situaciones. En todos los casos la situación se aleja del ideal de la competencia perfecta, en el que cada empresa es tan pequeña que cree que no puede hacer nada para influir en los precios. (2000, p. 92). 
Es así como los instrumentos de intervención del Estado para la corrección de las fallas del mercado, como el derecho de la competencia, se constituyen en una necesidad para garantizar el acceso a los mercados y la defensa de los derechos de los consumidores.

Sin embargo, el derecho de la competencia no solamente debe encargarse de la regulación de las estructuras de mercado distintas a la competencia perfecta, sino que también debe regular las prácticas de los competidores que tienden a restringir la libre competencia a otros participantes en el mercado, aunque se evidencie la existencia de varias empresas, pues como lo explica Posner:

El monopolio puede resultar también de la colusión entre empresas competitivas, de modo que debemos considerar los incentivos para innovar y reducir costos en un mercado que contiene más de una empresa, pero que está efectivamente cartelizado, y la entrada de nuevas empresas se encuentra obstruida. (2007, p. 441).

Con toda la problemática arriba expuesta, procede ahora realizar un análisis de ese marco jurídico de protección existente en el ordenamiento colombiano, desde sus fundamentos constitucionales y hasta la explicación de las principales prácticas restrictivas de la competencia tipificadas en nuestra normatividad vigente. Así como la existencia de una particular división del derecho mercantil encargada de regular las relaciones económicas desde el ámbito de la competencia económica.

\section{La competencia en el modelo jurídico-económico colombiano: derecho constitucional de la libre competencia económica en el marco de la economía social de mercado}

\subsection{La competencia económica en el sistema constitucional}

La Constitución Política de 1991 estatuyó el paradigma del Estado Social de Derecho como el modelo de Estado aplicable a nuestro país. Con ello dotó al Estado de múltiples instrumentos para el cumplimiento de los fines consagrados en el artículo 2 superior, según el cual, corresponde al poder estatal el servicio para la comunidad, la promoción de la prosperidad 
general, la garantía de la efectividad de los principios, derechos y deberes consagrados en la Constitución, la facilitación de la participación de todos en las decisiones que los afectan y en la vida económica, política, administrativa y cultural de la Nación, la defensa de la independencia nacional, la integridad territorial, la convivencia pacífica y la vigencia de un orden justo.

De esta manera, la misma Constitución colombiana dispuso de un conjunto de normas superiores, a través de las cuales estructuró las principales instituciones, con principios y reglas que se encargarían de la promoción de la prosperidad general, y de la participación de los ciudadanos en las decisiones de la vida económica del Estado.

Fue entonces -con las normas consagradas en el título XII del texto superior- como la Carta Política incorporó en su contenido normativo la denominada Constitución Económica, a partir de la cual consolidó un modelo jurídico-económico que, por su parte, determinaría el papel que cumplen el Estado y la sociedad en el propósito de generar desarrollo económico para nuestro país.

Así, la denominada Constitución Económica ha sido reconocida en el Estado colombiano como:

(...) la parte del Texto Fundamental que sienta los principios superiores que orientan y fundan la posición del Estado en relación con la economía y los derechos de los asociados en este mismo ámbito. (...) dicha parte de Constitución, se encuentra compuesta por: '(...) las normas constitucionales que ordenan la vida económica de la sociedad y establecen el marco jurídico esencial para la estructuración y funcionamiento de la actividad material productiva, señalando los fundamentos esenciales que deberán tener en cuenta los operadores económicos (...)'. (Corte Constitucional Colombiana, Sentencia C-865 de 2004).

De esta manera, como lo afirma Ariño, la Constitución Económica integra "(...) el conjunto de principios, criterios, valores y reglas fundamentales que presiden la vida económico-social de un país, según un orden que se encuentra reconocido en la Constitución." (2003, p. 175).

Esta Constitución Económica, instituida principalmente en las prescripciones contenidas en los artículos 333 y 334 de la Carta Política 
de 1991 -sin desconocer las demás normas que regulan el régimen económico, de la hacienda pública, y en aquellas donde se reconocen derechos de contenido económico- asumió la aplicación de un modelo jurídico-económico particular, que establece la gran importancia del sector privado como promotor del desarrollo y, a la vez, el papel que debe cumplir el Estado como director general de la economía.

El modelo jurídico-económico colombiano se ha fundamentado en el principio de neutralidad económica y, por consiguiente, las prescripciones normativas de la Constitución Económica no se direccionan hacia la aplicación de los postulados de un modelo específico de aquellos que han sido ideados por los distintos teóricos de la economía, sino que, por el contrario, permite a la autoridad estatal - según las necesidades evidenciadas en un contexto económico determinado - tomar las medidas pertinentes para afrontar las necesidades específicas de cada tiempo, y aplicando el principio democrático.

De allí que la denominada neutralidad económica de la Constitución, supone que:

La 'Constitución económica' colombiana no es indiferente a las políticas económicas (...) Sin embargo - por el juego de la democracia representativa y participativa que implica una posible alteración de mayorías que encarnan diversos programas económicos, (...) [en esta] no se haya constitucionalizado un modelo económico petrificado. Esto significa que el Congreso y el Ejecutivo pueden llevar a cabo distintas políticas económicas, siempre y cuando ellas tiendan de manera razonable a cumplir con las normas que regulan la actividad económica del Estado y velar por los derechos constitucionales (Corte Constitucional Colombiana, Sentencia C-265 de 1994).

En lo señalado se reconoce claramente que la Constitución en sí misma no asumió la aplicación de un único modelo económico, sino que, por el contrario, constituyó un modelo jurídico-económico conforme al cual la autoridad estatal puede -a través de la aplicación del principio democrático expresado en la elección del congreso y de un programa de gobierno que se consolida, en la elección presidencial y, con posterioridad a ella, en los planes de desarrollo- acoger los diversos instrumentos de desarrollo 
económico ideados por los distintos modelos, con el fin de satisfacer las necesidades de sus asociados. Además de generar la estabilización de la economía y la promoción del desarrollo económico.

Este modelo jurídico-económico, a la luz de los supuestos contenidos en los ya mencionados artículos 333 y 334 superiores, establece la aplicación de una economía de mercado (parecida a aquella libertad de mercado defendida a ultranza por los clásicos de la economía), integrada con unas amplias facultades otorgadas al Estado para dirigir, de manera general, la economía e intervenir en los mercados cuando estos no logren los cometidos propuestos.

De esta manera, el modelo de economía social de mercado, o de "economía de mercado con carácter social" -como se le ha denominado a este modelo jurídico-económico- "(...) adscribe al sistema económico de la Constitución lo libre económico con lo social, a la vez que la aplicación, también en el ámbito económico, del principio pro libertate como supuesto que integra la noción de Estado Social de Derecho." (Correa, 2009, p. 135).

La economía social de mercado se reconoce entonces como una "tercera vía" entre los modelos de libre mercado y de planificación de la economía, que se fundamenta en la aplicación de "(...) una economía de mercado basada en la libertad e iniciativa privada, que admite ciertas intervenciones del Estado (red de seguridad para garantizar una mínima cobertura y servicios a todos los ciudadanos) complementarias y compatibles con aquella." (Ariño, 2003, p. 177).

Así ha sido reconocido también por la Corte Constitucional Colombiana. En jurisprudencia reciente resolvió la exequibilidad parcial de la cláusula general de prácticas restrictivas de la competencia contenida en el artículo primero de la Ley 155 de 1959, donde explicó lo siguiente:

En materia económica la Carta de 1991 adoptó el modelo de economía social de mercado. En este sentido ha dicho la Corte Constitucional, que "el Estado Constitucional colombiano es incompatible tanto con un modelo del liberalismo económico clásico, en el que se proscribe la intervención estatal, como con modalidades de economía de planificación centralizada en las que el Estado es el único agente relevante del mercado y la producción de bienes y servicios es un monopolio público. En 
contrario, la Carta adopta un modelo de economía social de mercado, que reconoce a la empresa y, en general, a la iniciativa privada, la condición de motor de la economía, pero que limita razonable y proporcionalmente la libertad de empresa y la libre competencia económica, con el único propósito de cumplir fines constitucionalmente valiosos, destinados a la protección del interés general". De acuerdo con lo anterior, el texto constitucional fue dispuesto para una sociedad de mercado, es decir, para un tipo de organización que desarrolla procesos ágiles de intercambio, que buscan no sólo la satisfacción de necesidades básicas, sino también la obtención de ganancia, bajo el supuesto, según el cual, la actividad económica debe ser dinámica y estar en crecimiento, todo ello en un escenario (el mercado) fundado en la libertad de acción de los individuos (las libertades económicas), en el que "las leyes de producción, distribución, intercambio y consumo se sustraen a la reglamentación consiente y planificada de los individuos, cobrando vida propia. (Sentencia C-032 de 2017).

Bajo tales premisas es imperioso reconocer la importancia que la Constitución Económica le otorgó a la iniciativa privada - y con ello a la competencia económica - con la consolidación del modelo de economía social de mercado, en la que la sociedad de mercado y la protección y garantía de este, aparece como el factor más importante.

Por lo anterior es pertinente traer a colación la disposición contenida en el artículo 333 constitucional, el cual dispone que:

La actividad económica y la iniciativa privada son libres, dentro de los límites del bien común. Para su ejercicio, nadie podrá exigir permisos previos ni requisitos, sin autorización de la ley. La libre competencia económica es un derecho de todos que supone responsabilidades. La empresa, como base del desarrollo, tiene una función social que implica obligaciones. El Estado fortalecerá las organizaciones solidarias y estimulará el desarrollo empresarial. El Estado, por mandato de la ley, impedirá que se obstruya o se restrinja la libertad económica y evitará o controlará cualquier abuso que personas o empresas hagan de su posición dominante en el mercado nacional. La 
ley delimitará el alcance de la libertad económica cuando así lo exijan el interés social, el ambiente y el patrimonio cultural de la Nación.

De la anterior transcripción normativa, surgen algunos comentarios que coadyuvan a la comprensión del papel asumido por la libre competencia en el modelo económico de economía social de mercado:

Como primera medida se debe destacar el reconocimiento de la libertad económica o, en otras palabras, de la libre iniciativa privada, como un principio que fundamenta todo el accionar de los particulares y del Estado en el desarrollo de las relaciones económicas.

De esta manera, como lo reconoció la Corte Constitucional desde temprana jurisprudencia, la libertad económica “(...) corresponde a una facultad que tiene toda persona de realizar actividades de carácter económico, según sus preferencias o habilidades, con miras a crear, mantener o incrementar su patrimonio (...)" (Sentencia T-425 de 1992), y se convierte en un elemento indispensable para el reconocimiento de la libertad de competencia como derecho constitucional.

En tal sentido, la libertad económica es reconocida como el principio constitucional que inspira y ordena la actuación de los particulares en la dinámica económica y la aplicación de todos los instrumentos de política económica necesarios para cumplir con los cometidos dispuestos en la Constitución. Se desarrolla a través del reconocimiento y garantía efectiva principalmente de dos derechos de naturaleza económica: la libertad de empresa y la libre competencia.

\subsection{La libre competencia económica como derecho constitucional}

La comprensión de la libre competencia, como un auténtico derecho subjetivo parte del reconocimiento que la misma Constitución Política le ha otorgado al afirmar - en el artículo 333 - que esta corresponde a un derecho de todos que supone responsabilidades. De la misma manera el artículo establece que corresponde al Estado, por mandato de la Ley, impedir que la libertad económica se obstruya para evitar y controlar el abuso de la posición dominante, que tengan algunos agentes en el mercado, así como delimitar el alcance de este derecho. 
De esta manera se concretan las tres características reconocidas por Arango (2012, p. 9), para establecer que la libre competencia económica se constituye en un verdadero derecho subjetivo, pues: i) El derecho encuentra un reconocimiento normativo no solo en el artículo 333 de la Constitución, sino también en el literal i del artículo 4 de la ley 472 de 1998, que la reconoce como un derecho colectivo, y en otras normas de orden legal y reglamentario en las que se regulan las prácticas restrictivas de la competencia económica - que serán objeto de estudio en el siguiente acápite del presente trabajo - y las prácticas de competencias desleal reguladas en Ley 256 de 1996; ii) El derecho encuentra unos sujetos obligados que - derivados de la interpretación del artículo 333 constitucional - corresponden, por un lado, al Estado, quien debe garantizar que las libertades económicas no sean restringidas, y que los agentes no abusen de su posición dominante en el mercado y, por el otro lado, los mismos agentes económicos, pues el 333 superior admite que la competencia es un derecho de todos que supone responsabilidades; y iii) El derecho cuenta con los denominados poderes jurídicos para su reconocimiento o, lo que es lo mismo, goza de instrumentos jurídico-procesales para su protección.

Así también lo ha confirmado la Corte Constitucional - como máximo intérprete de la Constitución y órgano de cierre de la jurisdicción constitucional - al reconocer que:

La Constitución contempla la libre competencia como un derecho. La existencia del mismo presupone la garantía de las mencionadas condiciones, no sólo en el ámbito general de las actividades de regulación atenuada, propias de la libertad económica, sino también en aquellas actividades sujetas a una regulación intensa, pero en las cuales el legislador, al amparo de la Constitución, haya previsto la intervención de la empresa privada. Se tiene entonces que, a la luz de los principios expuestos, el Estado, para preservar los valores superiores, puede regular cualquier actividad económica libre introduciendo excepciones y restricciones sin que por ello pueda decirse que sufran menoscabo las libertades básicas que garantizan la existencia de la libre competencia" (Sentencia C-032 de 2017). 
En tal sentido, la Corte reconoce que el derecho a la libre competencia no es un derecho de carácter absoluto y que - por lo mismo - el Estado a través de las funciones asignadas en los artículos 333, 334, y en otras disposiciones de orden constitucional, puede intervenir para regular la libre competencia, y de esta manera garantizar su reconocimiento efectivo.

De la misma manera, el máximo tribunal constitucional colombiano dispuso precisar los contenidos esenciales del derecho constitucional de la libre competencia para lo cual concretó que:

La libre competencia, por su parte, consiste en la facultad que tienen todos los empresarios de orientar sus esfuerzos, factores empresariales y de producción a la conquista de un mercado, en un marco de igualdad de condiciones. Según la jurisprudencia constitucional, esta libertad comprende al menos tres prerrogativas: (i) La posibilidad de concurrir al mercado, (ii) La libertad de ofrecer las condiciones y ventajas comerciales que se estimen oportunas, y (iii) La posibilidad de contratar con cualquier consumidor o usuario. En este orden de ideas, esta libertad también es una garantía para los consumidores, quienes en virtud de ella pueden contratar con quien ofrezca las mejores condiciones dentro del marco de la ley y se benefician de las ventajas de la pluralidad de oferentes en términos de precio y calidad de los bienes y servicios, entre otros. (Sentencia C-909 de 2012).

Surgen entonces -en cabeza del Estado- múltiples obligaciones referidas al ámbito de protección de la libre competencia como derecho subjetivo, que se pueden sintetizar -como lo hace Correa- de la siguiente forma:

Las obligaciones específicas de protección contempladas ex constitutione frente a la libre competencia (...) consisten en que el Estado, por mandato de la ley: 1. 'Impedirá que se obstruya o restrinja la libertad económica'; 2. 'Evitará o controlará cualquier abuso que personas o empresas hagan de su posición dominante en el mercado nacional'; y 3. Intervendrá para promover la productividad y la competitividad. Las dos 
primeras se encuentran contempladas en el artículo 333 C.P., y

la segunda en el artículo 334 C.P. (2009, p. 577).

Corresponde ahora hacer un análisis de la forma cómo el ordenamiento jurídico colombiano ha abordado la obligación de frenar la restricción de la libertad económica e impedir el ejercicio abusivo de la posición dominante que ostentan algunos agentes en el mercado, a través del estudio de las denominadas prácticas restrictivas de la competencia.

\section{Aproximación al contenido y alcance de las prácticas restrictivas de la competencia en el ordenamiento jurídico colombiano}

Teniendo en cuenta el carácter económico de la libre competencia, según el cual esta corresponde al “(...) enfrentamiento de las empresas por la clientela.” (Velandia, 2011, p. 49), y la necesidad de que esta sea regulada para asegurar su garantía efectiva, tal y como fue abordado en el primer acápite de este trabajo, y considerando, además, que la misma ostenta un papel importante en la aplicación del sistema de economía social de mercado. Es preciso ahora determinar el objeto y ámbito de protección de las normas que regulan las prácticas restrictivas de la competencia en el derecho colombiano.

Para ello se precisa que el objeto de protección del derecho de la competencia:

(...) consistirá, desde el punto de vista normativo, en la ordenación de reglas de comportamiento de los empresarios relacionadas con sus competidores, con el mercado, con los consumidores, en las cuales se establecen prohibiciones expresas o limitaciones a la libertad de empresa o económica propiamente dicha. (Correa, 2009, p. 570).

En tal sentido, el derecho de la competencia se encarga de regular conductas, que - como se verá - no son ejecutadas únicamente por las empresas mercantiles que desarrollan actividades económicas en función de generar utilidad a sus socios, sino que se extienden a la actividad de sus representantes e integrantes. Lo cual amenaza o cercena el derecho que otros empresarios tienen de competir libremente. Atenta contra las 
dinámicas propias de los mercados y, por supuesto, también peligran los derechos de los consumidores

Así, por ejemplo, se limitan aquellos signos distintivos cuya notoriedad trasciende al generarse una confusión entre el nombre del producto y el signo al que se encuentra asociado. Ha habido casos célebres como 'Icopor' para designar al poliestireno expandido o 'Saltinas' para las galletas de soda saladas. En ambos casos dado que el consumidor asociaba directamente el nombre de la marca por el producto, el Estado intervino para cancelar las marcas por el fenómeno de vulgarización. Esto con la finalidad de evitar monopolios injustificados en el uso de las mismas (Vargas-Chaves $\&$ Rodríguez-Ramírez, 2013).

Es así como en el ordenamiento jurídico colombiano, se encuentran vigentes diversas disposiciones normativas cuya finalidad corresponde a la regulación de las conductas de los agentes económicos que participan en los mercados, y que tienden a vulnerar el derecho constitucional de la libre competencia económica.

Estas normas pueden agruparse según su ámbito de protección, pues algunas regulan los actos de los agentes económicos que restringen la competencia económica. Otras proscriben las prácticas de cartelización entre empresas. Otras regulan la posición de dominio que ostentan algunos agentes en el mercado. Algunas, por su parte, establecen prohibiciones de carácter general para la protección del derecho en el comercio.

En lo que sigue de texto se hará un análisis de esta normatividad, agrupando las prácticas restrictivas según su ámbito de protección. Se acudirá para su explicación a decisiones que han sido tomadas por la Superintendencia de Industria y Comercio. Esta es la autoridad administrativa encargada de velar por la libre competencia en Colombia y de sancionar todas las prácticas que tiendan a restringirla (Art. 6. Ley 1340 de 2009), con el fin de examinar con mayor claridad, la forma de concreción de las prácticas analizadas en casos de la vida real.

\subsection{La cláusula general de prohibición de prácticas restrictivas de la competencia}

La prohibición de ejecutar conductas que tiendan a cercenar el libre ejercicio de la competencia económica, está tipificada en el ordenamiento 
jurídico colombiano, en su sentido más amplio, en una prohibición denominada: cláusula general de prohibición de prácticas restrictivas de la competencia o prohibición general, contenida en el artículo primero de la Ley 155 de 1959, el cual dispone:

Quedan prohibidos los acuerdos o convenios que directa o indirectamente tengan por objeto limitar la producción, abastecimiento, distribución o consumo de materias primas, productos, mercancías o servicios nacionales o extranjeros, y en general toda clase de prácticas, procedimientos o sistemas tendientes a limitar la libre competencia, con el propósito de determinar o mantener precios inequitativos en perjuicio de los consumidores y de los productores de materias primas.

De acuerdo con lo anterior, la Corte Constitucional Colombiana ha entendido que esta prohibición general incorpora tres conductas que se encuentran proscritas en el ordenamiento jurídico colombiano y que - a la luz de las normas que protegen la libre competencia - deben ser sancionadas por la Superintendencia de Industria y Comercio cuando aquella las encuentre probadas, a saber: i) Los acuerdos que de manera directa o indirecta busquen limitar la producción, el abastecimiento, la distribución o consumo de materias primas, productos o mercancías; ii) Aquellas prácticas, procedimientos o sistemas que tiendan a limitar la libre competencia; $y$ adicionalmente iii) Todas aquellas prácticas, procedimientos o sistemas que tiendan a mantener o determinar precios inequitativos. (Sentencia C-032 de 2017).

En tal sentido, para generar una mejor comprensión acerca del tratamiento y aplicación de la cláusula general de prohibición aquí analizada, resulta pertinente hacer referencia a la Resolución No. 80847 de 2015, a través de la cual la Superintendencia de Industria y Comercio decide acerca de la conducta ejecutada por los ingenios azucareros ASOCAÑA, INGENIO RIOPAILA CASTILLA, INGENIO INCAUCA, INGENIO MANUELITA, INGENIO PROVIDENCIA, INGENIO MAYAGÜEZ, INGENIO LA CABAÑA, INGENIO PICHICHÍ, INGENIO RISARALDA, INGENIO SAN CARLOS, INGENIO CARMELITA, INGENIO CENTRAL TUMACO E INGENIO MARÍA LUISA, para determinar si infringieron la prohibición general contenida en el artículo 1 de la Ley 155 de 1959 y el numeral 4 del artículo 47 del Decreto 2153 de 1992, que proscribe los acuerdos que 
tienen por objeto o como efecto, la asignación de cuotas de producción o de suministro.

De la misma manera, la Superintendencia decidió en tal resolución sobre si las empresas CIAMSA, DICSA, INGENIO RIOPAILA CASTILLA, INGENIO INCAUCA, INGENIO MANUELITA, INGENIO PROVIDENCIA, INGENIO MAYAGÜEZ, INGENIO LA CABAÑA, INGENIO PICHICHÍ, INGENIO RISARALDA, INGENIO SAN CARLOS, INGENIO CARMELITA, INGENIO CENTRAL TUMACO E INGENIO MARÍA LUISA incurrieron en las conductas tipificadas en el artículo 1 de la Ley 155 de 1959 y el numeral 10 del artículo 47 del Decreto 2153 de 1992, que proscribe los acuerdos que tengan por objeto o como efecto impedir a terceros el acceso a los mercados o a los canales de comercialización.

La investigación tuvo su inicio con las denuncias presentadas por varias empresas en las que se determinó la presunta comisión de prácticas comerciales restrictivas de la competencia en el mercado del azúcar, relacionadas con el incremento exagerado de los precios y la reducción en su disponibilidad. Lo que traía como consecuencia una grave afectación a los consumidores y a los productores de bebidas y alimentos que utilizan el azúcar como insumo en sus procesos productivos.

De esta manera, la actuación de la autoridad de competencia se centró en la determinación de si ASOCAÑA, y los demás ingenios investigados cercenaron la cláusula de prohibición general al haber realizado un acuerdo para asignar cuotas de producción del azúcar en Colombia, y si ASOCAÑA, CIAMSA, DICSA y los demás ingenios violaron la prohibición general al haber realizado un acuerdo para impedir u obstruir el ingreso de terceros en el mercado del azúcar en Colombia.

Conforme con los medios probatorios recaudados en la Investigación, la autoridad de competencia decidió sancionar a ASOCAÑA, CIAMSA, DICSA Y DOCE INGENIOS MÁS, por haber encontrado probada la realización de un acuerdo para impedir u obstruir el ingreso de terceros en el mercado del azúcar en Colombia, y de esta manera haber violado la prohibición general y el numeral 10 del artículo 47 del Decreto 2153 de 1992, por lo que también sancionó a las personas naturales que incurrieron en las conductas necesarias para la configuración del acuerdo, en virtud de la disposición normativa contenida en el artículo 26 de la Ley 1340 
de 2009, que dispone la sanción de las personas naturales que colaboren, faciliten, autoricen, ejecuten o toleren las conductas anticompetitivas.

En relación con la violación del numeral 4 del artículo 47 del Decreto 2153 de 1992, la Superintendencia de Industria y Comercio ordenó archivar la investigación, teniendo en cuenta que, aunque se encontró probado que existió una asignación de cuotas entre los investigados, la misma se derivó de la forma como funcionaba el Fondo de Estabilización de Precios para los Azúcares Centrifugados, Las Melazas Derivadas de la Extracción o el Refinado de Azúcar y los Jarabes de Azúcar - FEPA, el cual es un mecanismo de intervención del Estado en la economía para la estabilización de precios y, por lo mismo, no resulta aplicable la respectiva sanción.

La Superintendencia encontró probados los cargos por los cuales se emitió la sanción al determinar dentro del proceso de investigación, que los ingenios azucareros intercambiaron ilegalmente información a través de diversos medios, entre los que se encuentran la participación en reuniones de junta directiva, reuniones de presidentes, gerentes, y distintos comités, el intercambio de correos electrónicos, entre otros medios probatorios. Información que, por su parte, era sensible y que estaba relacionada con la cantidad de azúcar que se debía exportar, estrategia de exportaciones, volumen de productos a exportar, entre otras, lo que impactaba la cantidad de azúcar que permanecería en el mercado y en consecuencia su precio, en el marco del FEPA. (p. 7).

Conforme con lo anterior, la Superintendencia encontró probado que las empresas investigadas realizaron practicas tendientes a impedir el acceso al mercado del azúcar en Colombia. Con el fin de mantener el mercado interno alejado de un escenario de libre competencia, a través de una estrategia conjunta para impedir las importaciones de azúcar provenientes de otros países. Entre la que se probaron acciones como las negociaciones con agentes del mercado boliviano para impedir el acceso del azúcar proveniente de ese país. O la solicitud de autorizaciones a ASOCAÑA para permitir la importación de azúcar costarricense, entre otras.

En relación con la prescripción contenida en la cláusula de prohibición general, la autoridad de competencia expresó que:

La norma transcrita cubre todos aquellos acuerdos que tengan como objeto la generación de obstáculos o barreras para que 
otros agentes económicos ingresen o participen libremente en determinado mercado, así como todos aquellos acuerdos que tengan por efecto la obstaculización o la generación artificial de barreras para que otros agentes económicos ingresen o participen libremente en un mercado. (Superintendencia de Industria y Comercio, Resolución No. 80847 de 2015, p. 69).

De lo anterior, se puede colegir, entonces, que el ámbito de protección de la denominada cláusula de prohibición general de la libre competencia, resulta extremadamente amplio, pues en ella se pueden subsumir todos los comportamientos ejecutados por los agentes que tiendan a cercenar la libre competencia económica.

\subsection{El abuso de la posición dominante}

En relación con este tipo de prácticas es necesario partir del reconocimiento que hace el mismo artículo 333 constitucional, relacionado con la legalidad de la posición dominante en el ordenamiento jurídico colombiano. Lo anterior quiere decir que el sistema de economía social de mercado, no proscribe que los agentes lleguen a consolidar una posición de dominio en el mercado, siempre que la misma se haya conseguido a partir de la ejecución de prácticas legítimas de competencia. Por el contrario, lo que se encuentra prohibido es que, en virtud de aquella posición de dominio, el agente económico obstruya el ejercicio de la libre competencia económica a otros agentes, concretándose de esta manera el abuso de una posición dominante en el mercado.

En tal sentido, por posición dominante en el mercado colombiano, se entiende:

(...) el poder de mercado que le permite a un ente económico, sustraerse a una competencia efectiva en una parte importante del mercado afectando la libertad económica y los intereses de los consumidores; poder que se manifiesta en la posibilidad de determinar, directa o indirectamente, las condiciones de un mercado (precios, condiciones de venta, volúmenes de producción, sistemas de distribución de bienes o servicios, etc.), por lo menos dentro de un grado relativamente amplio y apreciable, y que implica menor participación colectiva en 
la fijación de precios y cantidades, y correlativamente mayor unilateralidad y relevancia de las decisiones que sobre estos extremos adopten las fuerzas dominantes sustituyendo los mecanismos de mercado. (Almonacid y García, 1998, p. 175).

De la cita anterior se deben precisar dos aspectos, pues consideramos que el concepto de posición dominante se confunde con la noción de su abuso. Primero, la posición dominante en el mercado debe entenderse como aquel poder de mercado que un agente económico ha adquirido con la ejecución de prácticas legítimas de competencia, lo que - como ya se ha dicho - no encuentra prohibición en el ordenamiento jurídico colombiano. Tal poder de mercado, le permite al agente con posición de dominio la facultad o posibilidad de determinar de manera directa o indirecta las condiciones de un mercado. Segundo, el abuso de la posición de dominio implica que, a través del aprovechamiento del poder que ostenta quien la posee, el agente económico afecte, bien sea la libertad económica, o bien los derechos de los consumidores, a través de la fijación de precios o de condiciones de venta o de producción, entre otras posibles prácticas prohibidas.

De esta manera, como lo establece Velandia, "[a]busar de la posición de dominio significa obtener provecho de la posición de dominio, es decir obtener ganancia injustificada basada en la falta de competencia efectiva." (2011, p. 177).

Así, como lo expresa el mismo autor, el abuso de la posición dominante puede darse desde la consolidación de cuatro supuestos, que son:

a) El abuso por venta por debajo de costos. En el cual el competidor vende sus productos por debajo de su estructura de costos, con el fin de eliminar a un competidor en el mercado. (Velandia, 2011, p. 179);

b) El abuso por mercados subsidiados. Es un agente que participa en el mercado a través de diferentes líneas de producción, aprovecha la posición de dominio que ostenta en una línea aumentando los precios, para bajar los precios en la línea de producción en la que no cuenta con tal posición. De manera tal, que se saque ventaja en el mercado en el que no se cuenta con posición de dominio. (Velandia, 2011, p. 180); 
c) Abuso por discriminación. Donde “(...) el agente con posición de dominio favorece con un comportamiento a un distribuidor $y$ desfavorece a otro que compite con el primero, entre ellos existirá una diferencia competitiva creada injustamente por quien ostenta la posición de dominio." (Velandia, 2011, p. 184); y

d) Abuso por ventas subordinadas. Es cuando "[e]l agente aprovecha la necesidad del consumidor para obtener una mejor utilidad sin justa causa, porque ata otros productos $u$ obligaciones al inicial, lo que hace que el consumidor pague más por satisfacer su necesidad (...)" (Velandia, 2011, p. 185).

De esta manera, para comprender cómo funciona mejor la consolidación de una conducta de abuso de la posición de dominio, se precisa conocer la sanción impuesta por la Superintendencia de Industria y Comercio a la Empresa de Acueducto, Alcantarillado y Aseo de Bogotá E.S.P., a través de reciente resolución No. 14305 de 28 de febrero de 2018, por incurrir en la conducta anticompetitiva al haber instalado una platina reductora de caudal y una válvula reductora de presión, con el fin de sabotear la forma como la empresa COOPJARDÍN - a quien la primera le suministraba agua en bloque - atendía a sus usuarios. Para de esta forma quedarse con sus clientes y atender directamente el mercado de agua en el norte de Bogotá.

En la citada resolución la autoridad de competencia establece que la Empresa de Acueducto de Bogotá ostenta una posición de dominio en el mercado de suministro de agua en bloque en Bogotá, por ser el único prestador de ese servicio, y que las barreras de entrada al mismo mercado corresponden a “(...) (i) Restricciones en la disponibilidad natural del insumo, (ii) Altos costos de inversión, (iii) Economías de escala y (iv) Costos hundidos (Superintendencia de Industria y Comercio, Resolución 14305 de 2018, p. 17), por lo que no existe una posibilidad real o potencial de acceder a tal mercado.

Igualmente, la Superintendencia logra establecer la intención de la EAB en participar del mercado de comercialización de agua potable o la prestación del servicio público de acueducto a usuarios finales. Actividad 
económica que ejercía la empresa COOPJARDín, con los usuarios del norte de Bogotá.

De esta manera, la autoridad de competencia logró probar la conducta anticompetitiva ejercida por la EAB al instalar la válvula reductora de caudal, con el fin de eliminar la competencia ejercida por la empresa COOPJARDÍA, para lo cual la Superintendencia expresó lo siguiente:

Estando plenamente acreditado en la presente actuación administrativa que: (i) la EAB tiene posición de dominio en el mercado de suministro de agua en bloque en Bogotá y diez (10) municipios aledaños; (ii) que la EAB creó y ejecutó una política corporativa de eliminación del suministro de agua en bloque; (iii) que la EAB tenía la intención de reservarse para sí el mercado de comercialización de agua potable a usuarios finales en la ciudad de Bogotá, desplazando a COJARDíN; y (iv) que en el marco de la mencionada política la EAB instaló una válvula limitadora de caudal y dos platinas de orificio en la red de acueducto de COJARDÍN, el despacho (...) puede concluir sin espacio a duda, que la EAB abusó de su posición de dominio en el mercado de suministro de agua en bloque y con ello incurrió en las infracciones a la libre competencia previstas en los numerales 4 (venta a un comprador en condiciones diferentes de las que se ofrecen a otro comprador cuando sea con la intención de disminuir o eliminar la competencia en el mercado) y 6 (obstruir o impedir a terceros, el acceso a los mercados o a los canales de comercialización del artículo 50 del Decreto 2153 de 1992. (Superintendencia de Industria y Comercio, Resolución 14305 de 2018, p. 38).

De allí que la autoridad de competencia resolvió declarar que la EAB violó la libre competencia por haber abusado de su posición de dominio en el mercado de comercialización de agua en bloque de Bogotá, y también por haber incurrido en las conductas tipificadas en el artículo 1 de la Ley 155 de 1959, y de los numerales 4 y 6 del artículo 50 del Decreto 2153 de 1992, imponiendo una multa de más de veinte mil millones de pesos, además de sancionar a las personas naturales que incurrieron en la ejecución de la conducta de la EAB. 


\subsection{Los actos restrictivos de la competencia económica}

Según lo dispuesto en el numeral segundo del artículo 45 del Decreto 2153 de 1992, se consideran actos restrictivos de la competencia todos los comportamientos de quienes ejerzan una actividad económica que estén dirigidos a desconocer o anular la libre competencia económica de otros agentes en el mercado.

En tal sentido, como lo aclara Velandia:

Los actos restrictivos son comportamientos unilaterales dirigidos a todos los comerciantes [que] se diferencian de la posición de dominio en la medida en que para los actos restrictivos no se requiere un sujeto calificado específico, sino que agrupan prohibiciones dirigidas a todo el universo de comerciantes. (2011, p. 195).

Conforme a lo anterior, en el ordenamiento jurídico son considerados actos restrictivos de competencia económica aquellos consagrados en el artículo 48 del Decreto 2153 de 1992, que considera como contrarios a la libre competencia:

1. Infringir las normas sobre publicidad contenidas en el estatuto de protección al consumidor.

2. Influenciar a una empresa para que incremente los precios de sus productos o servicios o para que desista de su intención de rebajar los precios.

3. Negarse a vender o prestar servicios a una empresa o discriminar en contra de la misma cuando ello pueda entenderse como una retaliación a su política de precios.

De esta manera la Superintendencia de Industria y Comercio, mediante resolución No. 8231 de 2001, decidió imponer sanción a la empresa Casa Luker S.A., por haber incurrido en la conducta tipificada en el numeral 2 del artículo 48 del Decreto 2153 de 1992, al informarle a la empresa Makro de Colombia S.A., que participaría en el makro mail No. 18, otorgándoles un $7 \%$ de descuento que no podría hacerse transferible al público, influenciando a Makro para que incremente sus precios o desista de su intención de rebajarlos. 
En tal sentido, frente a este particular acto restrictivo, la superintendencia expresó que:

(...) lo que está reprimido en el número 2 del artículo 48 del Decreto 2153 de 1992 es que una empresa, agente activo, despliegue actividades orientadas a alterar el libre albedrío de otra, agente pasivo, respecto del precio de los bienes y servicios de esta, cuando la orientación esté encaminada a que la otra empresa aumente sus precios o desista de su intención de reducirlos. La infracción ocurrirá sin importar que se logre el resultado, ni el tamaño o el ascendente que el agente activo tenga sobre el agente pasivo. (Superintendencia de Industria y Comercio, Resolución No. 8231 de 2001, p. 17).

Así, la autoridad de competencia declaró que la empresa Casa Luker incurrió en una conducta ilegal por contravenir lo dispuesto en el numeral 2 del artículo 48 del Decreto 2153 de 1992.

\subsection{Los acuerdos de cartelización}

De conformidad con la prescripción contenida en el numeral primero del artículo 45 del Decreto 2153 de 1992, se entiende por acuerdo restrictivo de la competencia a todo contrato, convenio, concertación, práctica concertada o conscientemente paralela, celebrada entre dos o más empresas, con el fin de censurar o falsear el derecho que tienen otros agentes económicos en competir libremente tanto en el mercado como por el mercado.

En tal sentido, la doctrina jurídica ha entendido que estos acuerdos corresponden a “(...) comportamientos adelantados por dos o más empresas mediante los cuales arreglan su actuar dentro de un mercado, falseando la competencia, bien sea porque dejan de competir o porque pretenden eliminar a un competidor." (Velandia, 2011, p. 109).

Estos arreglos de actuar para dejar de competir o para eliminar competidores, han de establecerse a través de la celebración de acuerdos de voluntades (Gómez, 1998, p. 115) o de la concurrencia de diversas voluntades hacia el mismo fin, aunque de ellas no se evidencie la celebración formal de un acuerdo. Casos en los cuales estaremos frente a la celebración 
de contratos, convenios, concertaciones, o a la ejecución de prácticas concertadas que vulneran el derecho a competir.

Otra manera de ejecutar los también llamados carteles o acuerdos de cartelización, se logra a través de la comprobación - a partir de distintos medios probatorios - de la existencia de patrones de comportamiento semejantes o uniformes que, aunque no constituyan en si mismos acuerdos de voluntades, sí permiten inferir la actitud consciente de los competidores para cercenar la competencia económica, casos en los cuales estaremos frente a la ejecución de las denominadas prácticas conscientemente paralelas o paralelismo consciente.

La doctrina también ha reconocido la posibilidad de que estos acuerdos se celebren entre empresas que participan dentro de una misma escala o fase de la cadena de valor, cuya denominación corresponde a los acuerdos horizontales, y acuerdos entre empresas con presencia en diferentes etapas de la cadena de valor o acuerdos verticales. (Velandia, 2011, p. 110).

Desde esta perspectiva, los acuerdos horizontales son aquellos que se celebran entre empresas "(...) del mismo nivel productivo o de la distribución, vale decir, entre empresas colocadas en posición de competir (...) (Gómez, 1998, p. 117) y los cuerdos verticales corresponden a aquellos acuerdos:

(...) celebrados entre empresas situadas en distintas fases del proceso productivo o de la distribución (...) sería el caso por ejemplo, del productor que impone a los adquirentes de sus bienes el precio de venta o la limitante de venderle a tal o cual comprador, o de no utilizar determinados canales de distribución. (Gómez, 1998, p. 121).

Con todo lo anterior, es el artículo 47 del Decreto 2153 de 1992, la norma jurídica que tipifica de manera específica los acuerdos de cartelización, para lo cual establece que se consideran contrarios a la libre competencia, entre otros, los siguientes acuerdos:

1. Los que tengan por objeto o tengan como efecto la fijación directa o indirecta de precios. 
2. Los que tengan por objeto o tengan como efecto determinar condiciones de venta o comercialización discriminatoria para con terceros.

3. Los que tengan por objeto o tengan como efecto la repartición de mercados entre productores o distribuidores.

4. Los que tengan por objeto o tengan como efecto la asignación de cuotas de producción o de suministro.

5. Los que tengan por objeto o tengan como efecto la asignación, repartición o limitación de fuentes de abastecimiento de insumos productivos.

6. Los que tengan por objeto o tengan como efecto la limitación a los desarrollos técnicos.

7. Los que tengan por objeto o tengan como efecto subordinar el suministro de un producto a la aceptación de obligaciones adicionales, que por su naturaleza no constituían el objeto del negocio, sin perjuicio de lo establecido en otras disposiciones.

8. Los que tengan por objeto o tengan como efecto abstenerse de producir un bien o servicio o afectar sus niveles de producción.

9. Los que tengan por objeto la colusión en las licitaciones o concursos o los que tengan como efecto la distribución de adjudicaciones de contratos, distribución de concursos o fijación de términos de las propuestas.

10. Los que tengan por objeto o tengan como efecto impedir a terceros el acceso a los mercados o a los canales de comercialización.

De la norma transcrita se infiere una característica propia de la tipificación de los acuerdos como prácticas restrictivas de la competencia, la cual corresponde a la falta de necesidad de consolidación de los efectos de los contratos, convenios, o prácticas concertadas o conscientemente paralelas. Por el contrario, para que un agente económico incurra en tales conductas, es suficiente que se ponga de acuerdo con otro para falsear la competencia, sin necesidad de que sus efectos se ejecuten. 
Lo anterior se da teniendo en cuenta que cada una de las causales de concreción de acuerdos comerciales restrictivos, establece como conducta reprochable la celebración de acuerdos que tengan por objeto el desconocimiento de la libre competencia como derecho económico. Además, la norma establece que son igualmente sancionables las concertaciones que tengan como efecto falsear el derecho constitucional, lo que permite inferir la tipificación de ambos escenarios. Vale decir, aquellos que tienen por objeto cercenar la libre competencia sin importar si aquel objeto tuvo efectos, y si aquellos acuerdos lograron consolidar los efectos perseguidos en la realidad.

Por lo tanto, de la tipificación prevista en el artículo 47 del Decreto 2153 de 1992, en una interpretación integral con lo dispuesto en el numeral primero del artículo 45 del mismo decreto, se puede concluir que los acuerdos restrictivos de la competencia se pueden dar en dos escenarios: El primero es cuando se logra probar la existencia de un contrato, convenio, concertación o práctica concertada entre los agentes económicos para evadir la libre competencia, caso en el cual el acuerdo de voluntades se convierte en un elemento fundamental. El segundo escenario es cuando se logra probar patrones de comportamiento sistemáticos y conscientes en los que no se evidencia, en sentido formal, la celebración de un acuerdo.

Así lo reconoció la Superintendencia de Industria y Comercio en Resolución No. 81391 de 2017, en donde, además, dispuso cuáles son los medios probatorios necesarios para evidenciar la configuración de tales prácticas, para lo cual nos permitimos transcribir in extenso los apartes de la resolución que resultan pertinentes:

Como puede advertirse (...), los acuerdos anticompetitivos o carteles empresariales pueden manifestarse en dos modalidades diferentes, cada una de ellas con su respectivo estándar probatorio para acreditar su existencia en el mercado, división o clasificación que por demás está en la mayoría de los regímenes de competencia del mundo (...) la primera modalidad de acuerdo restrictivo de la libre competencia económica se presenta cuando, con cualquier elemento material probatorio se demuestra de forma directa la existencia del acuerdo, es decir, cuando en la actuación administrativa existen pruebas tales como la confesión de uno o varios 
cartelistas (que por ejemplo, puede haberse dado o no a través del programa de delación o de beneficios por colaboración); correos electrónicos que comprueban la existencia del cartel, su dinámica de funcionamiento y los intervinientes; mensajes a través de aplicaciones tecnológicas de mensajería instantánea como WhatsApp, Facebook, Google o similares; y otros documentos que contienen acuerdos, actas de Asambleas o de Junta Directiva, que le permiten a la Autoridad de Competencia concluir que existió un 'contrato, convenio, concertación o práctica concertada' (...) La segunda modalidad de acuerdo a la que alude el régimen (...) corresponde a la de 'práctica conscientemente paralela' (o 'paralelismo consciente'). (...) En este sentido, es importante tener claro que tanto en Colombia como en los demás países o jurisdicciones del mundo, el estándar de prueba para un cartel empresarial en la primera modalidad requiere prueba directa, la cual valga decirlo, no se requiere para demostrar la existencia de un acuerdo en la modalidad de práctica consciente paralela. De esta manera, la norma no exige y así lo ha reconocido la doctrina y la jurisprudencia, que la Autoridad de Competencia cuente con pruebas directas como contratos, actas de Asamblea o Junta Directiva o correos electrónicos para sancionar un acuerdo anticompetitivo en la modalidad de paralelismo consciente. (p. 79-81).

Se procederá entonces a explicar los anteriores escenarios, con fundamento en decisiones emitidas por la Superintendencia de Industria y Comercio.

\subsubsection{Contratos, convenios, concertaciones o prácticas concer- tadas}

Uno de los casos en los que la Superintendencia de Industria y Comercio sancionó recientemente la consolidación de un acuerdo restrictivo de la competencia, fue el denominado caso de las Agencias de Casting, en el cual, mediante Resolución No. 30300 de 2016, la autoridad de competencia analizó si las empresas investigadas incurrieron en la conducta anticompetitiva prevista en el numeral primero del artículo 47 del Decreto 2153 de 1992, que reprocha los acuerdos que tienen por objeto 
o como efecto la fijación directa o indirecta de precios, con ocasión de haber celebrado el denominado "Convenio de concertación entre agencias de casting".

El sustento fáctico de la investigación y la posterior sanción, encuentra su fundamento en la suscripción del convenio antes señalado, conforme al cual las agencias estipularon la fijación de tarifas mínimas que se cobrarían por la prestación de algunos de sus servicios, especialmente en lo relacionado con los servicios como modelo publicitario, documento que fue autenticado en la notaría 42 de Bogotá.

En tal sentido, la Superintendencia encontró probado que las empresas investigadas suscribieron el convenio indicado, que el mismo se presume auténtico, que ninguna de las investigadas lo tachó de falso y que, adicionalmente, en aquel se puede evidenciar de manera clara las partes que lo suscribieron y la calidad en la que actuaron. Adicionalmente, la Superintendencia encontró que el acuerdo suscrito tiene la potencialidad, capacidad, idoneidad y aptitud para restringir, limitar o eliminar la competencia del mercado, toda vez que en el mismo las empresas pactaron una tabla de tarifas que aplicarían para la prestación de algunos de sus servicios.

De esta manera, al encontrarse en evidencia la suscripción de un acuerdo claramente anticompetitivo, la Superintendencia de Industria y Comercio decidió declararla responsabilidad administrativa de las investigadas por la incursión en la conducta tipificada en el numeral primero del artículo 47 del Decreto 2153 de 1992 y sancionar a las empresas, así como a las personas naturales que intervinieron en la suscripción del Convenio de concertación entre agencias de casting.

Otro de los casos recientemente estudiados por la autoridad de competencia corresponde al denominado Cartel de los Pañales, en el que la Superintendencia de Industria y Comercio, mediante resolución No. 43218 de 2016, analizó las presuntas prácticas anticompetitivas cometidas por las empresas COLOMBIANA KIMBERLY COLPAPEL S.A., PRODUCTOS FAMILIA S.A., TECNOQUÍMICAS S.A., TECNOSUR S.A. Y DRYPERS ANDINA S.A., quienes infringieron el numeral primero del artículo 47 del Decreto 2153 de 1992, que proscribe los acuerdos de precios. 
Durante el trámite de la investigación las empresas Kimberly y Familia se acogieron al programa de beneficios por colaboración (delación) previsto en el artículo 14 de la Ley 1340 de 2009, y, a través de ello, confesaron su participación en prácticas anticompetitivas, reconociendo su responsabilidad, y aportando pruebas relevantes para determinar la participación de las demás empresas cartelizadas.

El acuerdo evidenciado a partir de la valoración probatoria consistió en que las empresas KIMBERLY, FAMILIA Y TECNOQUÍMICAS:

(...) participaron en una práctica anticompetitiva consistente en un cartel empresarial para fijar directa y/o indirectamente los precios de los pañales desechables para bebés comercializados por dichas empresas, que corresponden aproximadamente al 85\% del total de los pañales comercializados en Colombia, el cual tuvo lugar continuamente desde el 2001 hasta, por lo menos, el 2012. Las pruebas del expediente dan cuenta de que el cartel empresarial tuvo como propósito fijar artificialmente los precios de los pañales desechables para bebés, comercializados por KIMBERLY, FAMILIA y TECNOQUÍMICAS, en detrimento de los consumidores, tanto usuarios del producto como empresarios intermediarios en la cadena de producción. Así, se encontró demostrado que, en ejecución del cartel empresarial, KIMBERLY, FAMILIA y TECNOQUÍMICAS, acordaron no solo renunciar a competir en precios para evitar que continuaran disminuyendo sus ganancias debido a la intensa competencia, sino que se pusieron de acuerdo para incrementar los precios de los pañales desechables para bebés comercializados. Adicionalmente, las empresas cartelizadas no solo fijaron directamente los precios de los pañales desechables para bebés, sino que también concentraron sus esfuerzos en eliminar o, por lo menos, disminuir las promociones y obsequios de los que gozaban los consumidores, lo que constituye un claro acuerdo anticompetitivo de fijación indirecta de precios." (Superintendencia de Industria y Comercio, Resolución No. 43218 de 2016, p. 50).

El sustento probatorio para la corroboración de la comisión de la práctica anticompetitiva se basó esencialmente en las confesiones de los 
delatores y en la información por ellos suministrada, en el marco del convenio de colaboración suscrito con la autoridad de competencia. A partir de tales pruebas se logró evidenciar el acuerdo de cartelización y, adicional con esto, se determinó que los acuerdos de precios se lograban a partir de reuniones clandestinas que sostenían los representantes de las investigadas, con el fin de dotar a tales reuniones de exclusividad, y de esta manera evitar que fuesen puestos en evidencia en la ejecución de los acuerdos ilegales.

Con fundamento en lo anterior, la Superintendencia de Industria y Comercio resuelve declarar a KIMBERLY, FAMILIA y TECNOQUÍMICAS, responsables de la violación de la libre competencia por haber actuado en contravención del numeral 1 del artículo 47 del Decreto 2153 de 1992, por haber efectuado un acuerdo de precios para la comercialización de pañales desechables de bebés, para lo cual decide sancionar a estas empresas, declarando a su vez que KIMBERLY y FAMILIA cumplieron con el programa de beneficios por colaboración y, en consecuencia, se hicieron adjudicatarias de la exoneración y reducción del pago de la multa correspondiente.

Así mismo, la autoridad de competencia decidió sancionar a las personas naturales que intervinieron en la ejecución de la práctica anticompetitiva.

\subsubsection{Paralelismo consciente}

El paralelismo consciente o ejecución de prácticas conscientemente paralelas fue analizado y explicado con gran profundidad en la sanción impuesta por la Superintendencia de Industria y Comercio a las empresas cementeras ARGOS, CEMEX y HOLCIM, mediante Resolución No. 81391 de 2017. En la que se resuelve la incursión de las investigadas en conductas de acuerdo para la fijación de precios y de acuerdo para la repartición de mercados, tipificadas en los numerales 1 y 3 del artículo 47 del Decreto 2153 de 1992, y en conductas tipificadas en la prohibición general contenida en el artículo primero de la Ley 155 de 1959.

Luego de efectuar un análisis de la estructura de mercado, en la cual las empresas comercializaban el cemento gris Pórtland tipo 1. La superintendencia concluyó que el mismo no encuentra productos sustitutos 
en el mercado, por lo que se configura la insustituibilidad de la demanda (p. 45), así como la dificultad de que otras empresas, en el corto plazo, puedan entrar a competir en la industria de ese producto debido a que la infraestructura para ello corresponde a una infraestructura especializada para la producción, por lo que se consolida la insustituibilidad de la oferta en este mercado.

De la misma manera, la superintendencia concluye que el mercado cuenta con varias barreras estructurales de acceso (p. 51), entre las que se encuentra la alta inversión inicial para acceder a la industria, los costos irrecuperables en caso de que un agente entre al mercado y decida posteriormente no participar en él, la existencia de economías de escala (p. 52), entre otras barreras de acceso.

Adicionalmente la superintendencia concluye que el producto comercializado posee un alto grado de homogeneidad en relación con el que ofrecen en el mercado las empresas investigadas (p. 54), y, por lo mismo, aunado a la existencia de barreras estructurales de entrada, se consolida una alta concentración de poder de mercado en ellas (p. 55).

Con las características del mercado específico en el que desarrollan sus actividades económicas, la superintendencia logra evidenciar que en las empresas investigadas existe un acuerdo de precios en la modalidad de paralelismo consciente o práctica conscientemente paralela, sobre lo cual refirió que:

(...) para configurar una práctica de fijación de precios conscientemente paralela, basta que se advierta y compruebe una simetría de precios en un período de tiempo dado, con variaciones homólogas y tendencias homogéneas, siempre y cuando tal simetría esté acompañada de factores adicionales que denoten que el comportamiento de los precios responde a una concertación entre los agentes involucrados o a una abstinencia de competencia y no a variables de otra naturaleza. (...) Así, para tipificar un acuerdo cartelista en la modalidad de práctica conscientemente paralela, debe hacerse una valoración conjunta del paralelismo y de los factores plus que conforman el elemento consciente, pues solo a partir de la conexión entre todos estos elementos puede determinarse la existencia de un 
acuerdo anticompetitivo y descartar la existencia de cualquier otro fenómeno que pudiera justificar el panorama económico simétrico, objeto de reproche. (Superintendencia de Industria y Comercio, Resolución No. 81391 de 2017, p. 81).

En relación con la existencia de los denominados factores plus - a partir de un análisis de algunas propuestas formuladas por ciertas posturas teóricas - la superintendencia los entiende como factores que dan evidencia relevante para establecer si un mercado determinado es propenso a la formación de carteles, y que constituyen “(...) una serie de criterios líderes que pueden constituir factores plus relevantes a efectos de caracterizar completamente dicha conducta." (Superintendencia de Industria y Comercio, Resolución No. 81391 de 2017, p. 82).

En tal sentido, habiendo hecho el respectivo análisis probatorio, la autoridad de competencia encontró demostrado un patrón de comportamiento semejante de los precios ex fábrica de las empresas investigadas, con tendencia decreciente a finales de 2010, y creciente a partir de enero de 2011 y hasta finales de 2012, lapso que constituye el período investigado.

Tal patrón de comportamiento en los precios, constitutivo del paralelismo, fue soportado de manera probatoria en la aplicación de un análisis estadístico cuyos resultados arrojaron un alto grado de asociación directo, casi perfecto, entre los precios de los investigados en el período de análisis.

Por su parte, el elemento de consciencia de la conducta fue probado a partir del análisis de - entre otros medios de prueba - algunos correos electrónicos en los que una de las empresas, al responder el correo en el que le solicitaban a todas una cotización, dio a conocer a sus competidores la estructura de precios que estaba manejando, lo que la Superintendencia entendió, no como un simple error, sino como el indicio de la consolidación del paralelismo estudiado.

De la misma manera, la Superintendencia infirió la existencia de la práctica consciente al evidenciar - según comunicaciones compartidas entre las empresas por diferentes medios - que las investigadas daban aplicación del denominado principio de no meterse en obras comenzadas. Una vez que una empresa haya suministrado los insumos para el inicio de 
una obra nueva, las otras no debían entrometerse con política de precios, para atraer la venta hacia sus arcas.

La autoridad de competencia entendió que la aplicación de tal principio constituía una práctica concertada entre las investigadas, que se ejecutaba de manera consciente, por lo que encontró que el acuerdo de precios se había desarrollado en la modalidad de paralelismo consciente.

De esta manera, la Superintendencia de Industria y Comercio decide sancionar a las empresas ARGOS, CEMEX Y HOLCIM, por haber incurrido en un acuerdo de precios en la modalidad de práctica conscientemente paralela, y sancionar a algunos de sus representantes legales e intervinientes con fundamento en lo dispuesto en el numeral 16 del artículo 4 del Decreto 2153 de 1992.

En relación con los cargos relacionados con la repartición de mercados y la aplicación de la prohibición general, la Superintendencia no encontró el soporte probatorio necesario, por lo que decidió no sancionar por estas causas.

\section{Conclusiones}

El derecho de la libre competencia económica ostenta una singular relevancia en el ordenamiento jurídico colombiano, ya que es a partir de su reconocimiento cuando se garantiza la posibilidad de ejercer actividades económicas sin la existencia de barreras injustificadas en el marco del modelo jurídico-económico de Economía Social de Mercado, instituido en nuestro sistema jurídico a partir de la expedición de la Constitución Política de 1991.

De esta manera, la regulación estatal en relación con la libre competencia económica, encuentra su justificación en el cumplimiento del deber constitucional y legal, de no falsear la competencia a través de la imposición de barreras injustificadas, pues en el ordenamiento jurídico colombiano tales barreras o limitaciones solo se pueden incorporar en virtud de un mandato legal.

Así, la regulación de la competencia en el derecho colombiano encuentra en la tipificación de las prácticas restrictivas un instrumento 
adecuado para la protección y garantía efectiva del derecho constitucional de naturaleza individual y colectiva (Rodríguez \& Vargas-Chaves, 2014).

Con todo el desarrollo anterior, el ordenamiento jurídico proscribe toda conducta que falsee el ejercicio de la libre competencia económica, tipificando conductas individuales de los agentes económicos como los denominados actos restrictivos consagrados en el artículo 48 del Decreto 2153 de 1992, los acuerdos restrictivos previstos en artículo 47 de la citada norma, así como el abuso de la posición de dominio, consagrado en el artículo 50 de la misma norma.

\section{Referencias}

Arango, R. (2012). El concepto de derechos sociales fundamentales. $2^{\mathrm{a}} \mathrm{Ed}$. Bogotá: Colombia. Legis S.A.

Ariño, G. (2003). Principios de Derecho Público Económico. Modelo de estado, gestión pública, regulación económica. Bogotá: Colombia. Universidad Externado de Colombia.

Brue, S. L. \& Grant, R. R. (2009). Historia del pensamiento económico. $7^{\mathrm{a}}$ Ed. Ciudad de México: México. Cengage Learning Editores, S.A.

Constitución Política de Colombia. [Const.]. Julio 7 de 1991 (Colombia).

Correa, M. (2009). La libertad de empresa en el Estado Social de Derecho. Bogotá, Colombia: Universidad Externado de Colombia.

Corte Constitucional Colombiana. Sala Plena. Sentencia T-425 (M.P. Ciro Angarita Barón; Junio, 24, 1992).

Corte Constitucional Colombiana. Sala Plena. Sentencia C-265 (M.P. Alejandro Martínez Caballero; Junio, 02, 1994).

Corte Constitucional Colombiana. Sala Plena. Sentencia C-865 (M.P. Rodrigo Escobar Gil; Septiembre, 07, 2004).

Corte Constitucional Colombiana. Sala Plena. Sentencia C-909 (M.P. Nilson Pinilla Pinilla; Noviembre, 07, 2012).

Corte Constitucional Colombiana. Sala Plena. Sentencia C-032 (M.P. Alberto Rojas Ríos; Enero, 25, 2017).

Decreto 2153 de 1992. Por el cual se reestructura la Superintendencia de Industria y Comercio y se dictan otras disposiciones. (Diciembre 30 de 1992. D.O. No. 40.704). 
Gómez, D. (1998). De las restricciones, del abuso y de la deslealtad en la competencia económica. Bogotá: Colombia. Cámara de Comercio de Bogotá.

Krugman, P., Wells, R., \& Graddy, K. (2013). Fundamentos de economía. 2a Ed. Barcelona: España. Editorial Reverté.

Mankiw, N. G. (2012). Principios de economía. 6 $6^{\mathrm{a}}$ Ed. Mexico: engage Learning Editores, S.A. de C.V.

Parkin, M. (2014). Economía. 11ª Ed. Naucalpan de Juárez: México. Pearson Educación de México, S.A. de C.V.

Pindyck, R. \& Rubinfeld, D. (2009). Microeconomía. Madrid, España: Pearson Educación S.A.

Posner, R. (2007). El análisis económico del derecho. 2a Ed. México D.F. Fondo de cultura económica.

Rodríguez, G.A., \& Vargas-Chaves, I. (2014) Políticas de igualdad e intereses colectivos. Bogotá: Grupo Editorial Ibáñez.

Smith, A. [1776] (1994). Una Investigación sobre la Naturaleza y las Causas de la Riqueza de las Naciones. Madrid; España: Alianza Editorial S.A.

Stiglitz. J. (2000). La economía del Sector Público. $3^{a}$ Ed. Barcelona: España. Antoni Bosch, Editor.

Superintendencia de Industria y Comercio de Colombia. (2001). Resolución 8231. Recuperado de http://www.sic.gov.co/recursos user/ documentos/normatividad/Publicaciones_Despacho_3/sicdecisiones2/RESOLUCIONES_COMPETENCIA_ANOS/2001/RESOLUCION_8231_DE_21_DE_MARZO_DE_2001.pdf

Superintendencia de Industria y Comercio de Colombia. (2016). Resolución 30300. Recuperado de http://www.sic.gov.co/sites/default/files/ estados/RESOLUCION_30300_AGENCIAS_DE_CASTING_23 MAY_2016.pdf

Superintendencia de Industria y Comercio de Colombia. (2017). Resolución 81391. Recuperado de http://www.sic.gov.co/sites/default/files/files/Normativa/Resoluciones/Resolucion 81391 2017.pdf

Superintendencia de Industria y Comercio de Colombia. (2018). Resolución 14305. Recuperado de http://www.sic.gov.co/sites/default/ 
files/estados/052018/Resolucion 14305 IMPONE MULTA VENTA DE AGUA EN BLOQUE PUBLICA.pdf

Tirole, J. (2017). La economía del bien común ¿Qué ha sido de la búsqueda del bien común? ¿En qué medida la economía puede contribuir a su realización? Bogotá: Colombia. Taurus.

Vargas-Chaves, I., \& Rodríguez, S. (2013) La caducidad por vulgarización en la marca y su efecto estabilizador en los mercados. Panorama, 8(12), 127-137.

Velandia, M. (2011). Derecho de la competencia y del consumo. Competencia desleal; abuso de la posición de dominio; carteles restrictivos: actos restrictivos; integraciones económicas y protección al consumidor. $2^{\mathrm{a}}$ Ed. Bogotá: Colombia. Universidad Externado de Colombia. 